\title{
A Pedagogia como Ciência A instituição da Ciência Pedagógica
}

\section{Resumo}

Para se reconhecer a autonomia epistemológica de uma ciência específica da educação, é necessário precisar a natureza do seu objeto e seus métodos de estudo. É indubitável que a discussão do estatuto epistemológico da ciência pedagógica se deva realizar no contexto de uma reflexão epistemológica própria. Para isso, recorremos à epistemologia específica da educação. $\bigcirc$ que significa dizer que a educação é um objeto dinâmico, em construção, portador de finalidade e perspectivas temporais, que torna complexo seu conhecimento.

objeto refere-se à educação e seu método necessita de uma concepção que represente o "universal concreto", que forneça leis objetivas, as quais sejam, ao mesmo tempo, leis de todo o movimento, tanto do real quanto do pensamento. Este método é o dialético. Sua existência possibilita definir a pedagogia como ciência autônoma da educação, pois leva à compreensão do fato educacional em seu movimento e em seu campo de intersubjetividades, assim, permite compreender a pedagogia como um campo de estudo concreto da realidade educacional.

\section{Abstract \\ In order to recognize the epistemic autonomy of a specific educational science, it's necessary to achieve the nature of its object and its methods of investigation. It's indubitable that the discussion about pedagogical science epistemic statute must be done in the context of a particular epistemic reflection. For this, we can make use of a specific educational epistemology, it means that education has to be considered as a dynamic object, in construction, carrying goals and temporal perspectives,}

what confer to the knowledge itself high complexity.

The education is the object of investigation and the methodology to be used must have a theorical conceptual scheme as a representation of a "concrete universe" that provides objective laws which be at the same time laws of the whole movement as the actual so the abstract thought. This method is the dialectic which permits top define the pedagogy as an education autonomous science, since it conducts to understand the educational fact in its movement and its intersubjectively field as well. So, it permits to understand the pedagogy as a concrete field of study on educational reality.

A reflexão sobre o conhecimento epistemológico da pedagogia hoje é necessária, para que os educadores/educadoras adquiram consciência de sua própria posição pedagógica no sentido de estabelecer uma praxis coerente com sua visão de mundo.

No mundo atual, com a expansão da tecnologia e da ciência, é necessário reconhecer o tipo de conhecimento pedagógico que os educadores/educadoras adquirem, para que ele possa assumir a sua real importância. A pedagogia, em determinados momentos históricos, tem apresentado o seu conhecimento: como senso comum, assistemático; como arte, regras capazes de dirigir uma atividade humana qualquer; como tecnologia, estudo dos processos técnicos de um determinado ramo de produção. As variantes dessas definições de pedagogias traduzem para a perspectiva da modernidade na sociedade capitalista um estudo apenas especulativo.

Conhecer o significado necessário da epistemologia pedagógica é de importância fundamental para a educação atual, no sentido de se buscar a praxis pedagógica na construção de uma educação cien-

*Doutora em Educação: Didática, USP. Mestre em Educação: História e Filosofia da Educação. Licenciada e Bacharel em Filosofia. Professora das Faculdades Integradas "Campos Salles". 
tífica. É possível que os educadores/educadoras tenham uma atitude de praxis, mas vai depender de sua concepção pedagógica, para que realmente se constitua numa atitude de reflexão-ação. Mas qual é esta concepção e/ou epistemologia dessa pedagogia?

A concepção parte da compreensão da educação como relação social e como tal participa das relações humanas (homem - economia; homem social; homem - psique; homem - transcendência), sendo que as relações estão intrinsecamente relacionadas, elas participam da totalidade das relações de produção ${ }^{l}$, nesta perspectiva a educação pertence a produção social no contexto em que atua.

Falar das quatro relações é o mesmo que citar a relação homem - mundo que se traduz pela produção humana e que, por sua vez, significa cultura, pois não existe sociedade sem ela e vice-versa. A cultura diz respeito, então, à produção e reprodução da existência humana, o que constrói diferentes elos de significação na relação homem mundo. Isto significa que na cultura (produção histórica coletiva dos seres humanos) está inserida a prática educativa, ao formar e informar os indivíduos para que produzam sua existência. Assim, seu objetivo primordial é identificar os elementos culturais que devem ser preservados e, ao mesmo tempo, descobrir as situações que estão impedindo a própria existência humana, para transformá-las a partir delas.

Desse modo, a educação é vital para a humanização dos seres humanos, propiciando uma continuidade ou ruptura pelas quais a cultura se mantém e modifica os indivíduos em sua história. Nessa visão de educação como prática social decorrente da existência humana, por reproduzir e produzir relações presentes nas instituições sociais e, por conseguinte, ter fins específicos definidos por aspirações e interessès presentes num contexto histórico, ela também possui uma função política.

Depreender o caráter social e político da educação é compreender que a cultura é determinada pelas realidades econômicas, sociais e políticas estabelecidas pelas relações entre os homens. Essas relações ocorrem em função de finalidades e obje- tivos correspondentes a determinada sociedade e carregam uma intencionalidade explícita ou implícita de poder.

Assim, a educação reflete e ajuda a modificar a própria constituição social através de sua função política, possibilitando que ela seja dinâmica ao garantir as modificações necessárias à sociedade de um determinado momento histórico para outro. Seja no momento da acumulação primitiva, ou no capitalismo concorrencial, ou no capitalismo monopolista, que envolve relações entre os homens de diferentes modos. Ou seja, a cada momento, a educação tem uma relação intrínseca com a sociedade, modificando-se no movimento em que a sociedade se modifica.

É por esse caráter mutável e transitório da prática educativa que as questões estudadas pela pedagogia também se mostram mutáveis e transitórias. A teoria pedagógica reflete essa prática educativa, investiga a natureza das finalidades da educação em determinada sociedade, indica os meios apropriados para a formação dos indivíduos com o fim de prepará-los para as práticas sociais. A pedagogia, então, revela as diferentes formas de organização, de direção, de sentido, de finalidade das práticas educativas, dando lugar a diferentes concepções.

Com essa visão sobre a educação e a pedagogia, pode-se destacar, por um lado, que a educação é ação ou prática e, de outro, que a pedagogia é reflexão ou teoria sobre aquela. Sendo assim, ambas integram a totalidade do campo educacional.

Pode-se dar dois sentidos de pedagogia: prática, arte ou profissão do educador e qualquer teoria sobre a educação - teoria compreendida não só como uma elaboração ordenada e generalizada das modalidades e das possibilidades da educação, mas também como reflexão ocasional ou um pressuposto qualquer da prática educativa. Apesar desses dois sentidos terem surgido separadamente na antiguidade clássica, um de natureza filosófica e outro de natureza empírica ou prática, permanecem até hoje. Os dois entendimentos, seja na antiguidade, seja na atualidade, não dão à pedagogia o caráter de ciência da educação.

Se a pedagogia continuar sendo concebida 
como experiências isoladas, a métodos pessoais, ela estará refletindo sobre um ideal variável de acordo com o pensamento de cada indivíduo ou grupos de indivíduos. Será então definida como arte da educação $o^{2}$, já que não poderá ser uma ciência, por dizer respeito à dimensão especulativa e subjetiva. Quando a reflexão pedagógica recai sobre a educação no tempo e no espaço, ela é considerada História da Educação e, por outro lado, ela se volta para campos de especialização diferentes, é encarada como Filosofia da Educação. Neste sentido, a pedagogia apresenta-se encoberta por outros campos de conhecimentos.

Porém, assumir a pedagogia como reflexão sobre os fatos da educação - pertencentes ao seu domínio, e não ao de outras especializações —, ela é definida como ciência autônoma da educação, como defende Mialaret ${ }^{3}$, entre outros.

Para sua reflexão, a pedagogia depende de outras ciências, assim como outras precisam dela, ainda que cada qual com seu objeto de estudo. Por exemplo: se o objeto de estudo da história da educação é o espaço e o tempo da educação, o objeto da pedagogia é a educação no espaço e no tempo, ou seja, a pedagogia historiciza a educação.

Para reconhecer a autonomia epistemológica de uma ciência específica da educação, é necessário precisar a natureza do seu objeto e seus métodos de estudo. É indubitável que a discussão do estatuto epistemológico da ciência da educação, ou pedagogia, se deva realizar no contexto de uma reflexão epistemológica própria. Para isso, recorre mos à epistemologia específica da educação.

A educação, como vimos, é um campo eminentemente humano mutável através do tempo. Isso significa que a educação é um objeto dinâmico, em construção, portador de finalidades e perspectivas temporais, o que torna complexo o seu conhecimento. Resta frisar que ela pertence a um campo que se modifica parcialmente também quando se tenta conhecê-lo, do mesmo modo que provoca mudanças naquele que procura conhecê-lo. Assim, há um reconhecimento na valorização do conhecimento pedagógico como subjetivo-objetivo e/ou objetivo-subjetivo. Nesse sentido, tanto sujeito como objeto se fazem no âmbito da relação do conhecimento pedagógico.

Essa relação do conhecimento, em nosso campo específico, ocorre entre o pedagogo e a educação, pólos em movimento. Daí explicitamos que a pedagogia também está em movimento. Para definir esse conhecimento pedagógico como ciência, é necessário distinguir a pedagogia pelo método de investigação, o qual precisa captar a dinâmica do campo educacional.

O conhecimento científico volta-se, através do método, principalmente para a concretude do real, ou seja, pretende ser um saber real, e um saber realé um saber do real $l^{4}$. Para tanto, é necessário um método cuja concepção represente o universal concreto, que forneça leis objetivas, as quais sejam, ao mesmo tempo, leis de todo o movimento, tanto do real quanto do pensamento, do objetivo e do subjetivo.

método científico compreende a lógica geral, tácita ou explicitamente empregada para apreciar o mérito de uma pesquisa, o processo de reflexão que vai do abstrato ao concreto, para se apossar deste e apresentá-lo como concreto pensado ${ }^{5}$. Esse método lógico inerente à ciência é o instrumento para atingir conclusões fundadas acerca do mundo em que os homens vivem e do lugar que nele ocupam, pois possibilita captar a realidade em movimento. Assim, as leis de tal método - internas ao conhecimento e ao conhecido, o objeto - devem ser concretas.

Todas essas caracterizações de método nos reportam, efetivamente, ao método dialético. Sua existência possibilita definir a pedagogia como ciência autônoma da educação, pois leva à compreensão do fenômeno da educação em seu movimento e em sua complexidade e permite também compreender a pedagogia como um campo de estudo concreto da realidade educacional.

Pode ainda restar uma dúvida, para que possamos classificar a pedagogia como ciência, destacando-a dos

DEBESE e MIALARET; 1974:3-4

${ }^{3}$ MIALARET; 1977:13

"JEAN LADRIÉRE (1978:35)

${ }^{5}$ MARX; 1982:14 
domínios de outras ciências, como a história da educação: que características da pedagogia lhe garantem a condição de ciência autônoma?

Primeiro, é preciso partir da idéia de que qualquer área do conhecimento científico abrange apenas e tão-somente o universo em que seus conceitos, suas leis, seus procedimentos se inscrevem. Entretanto, não existe ciência solitária; cada uma dá suas contribuições às demais, criando condições para um conhecimento interdisciplinar. $\mathrm{O}$ mesmo ocorre com a pedagogia.

Segundo, a pedagogia, definida como ciência autônoma, tem um objeto que lhe é próprio, a educação, a ação educativa, e faz uso de um método que pertence ao campo da lógica dialética. Assim, a pedagogia destaca-se de outros campos científicos por seu objeto, suas hipóteses e sua teoria específicos e busca a concretude do real ou um saber do real através de um método que apreende o movimento.

E o que diferencia a pedagogia como ciência da educação de outras ciências da educação? A pedagogia busca analisar tanto o produto da ação educacional — o qual descreve, explica, interpreta quanto seu processo - algo que se deve fazer, produzir, realizar. Assim, podemos considerar a pedagogia como ciência que procura sistematizar a educação, uma teoria construída a partir e em função das exigências educacionais, ou seja, realidade-processo e realidade-produto.

Essas características da pedagogia — ciência que trata do processo e do produto da educação — só encontram respaldo no método dialético. Os outros métodos, além de não abrangerem a educação, também não captam o movimento do sujeito e do objeto, proporcionando uma compreensão parcial, temporal e estagnada do campo educacional. O métodó dialético, de seu lado, leva em conta as partes para a compreensão da totalidade do próprio objeto, a educação, e conta com lêis que permitem a relação entre o produto e o processo educacional no decorrer do próprio processo. São elas, como afirma Lefebvre ${ }^{6}$, a lei da conexão universal; a lei do movimento universal; a lei da unidade dos contrários; a lei da transformação da quantidade em qualidade; a lei da superação.
Essas leis, transitoriamente relacionadas, possibilitam uma análise objetiva tanto do processo quanto do produto educacional, dois elementos em constante interação. Assim, estão sempre em movimento, pois, ao se analisar um processo, chegase a um produto que, por sua vez, pode ser analisado novamente, gerando novo produto. $\mathrm{O}$ novo processo é a superação do processo e do produto primeiro, pois são opostos, contraditórios, e, num determinado momento de quantidade, levam o novo processo a uma qualidade diferenciada.

A compreensão do método dialético só se tornou possível com o advento do capitalismo. $\mathrm{Na}$ acumulação primitiva do capitalismo, a visão de mundo ocidental transformou-se. E não só a visão de mundo (superestrutura), mas também o modo de produção (estrutura) já se vinha modificando, um influenciando o outro. A estrutura, no entanto, determinava a superestrutura, pois já alcançara um grande desenvolvimento no campo da técnica e das relações de produção.

Essa nova visão de mundo do homem em transição fez emergir as próprias ciências humanas desvinculadas da filosofia - a sociologia, a psicologia, a história, a economia e, mais recentemente, a pedagogia - , decorrentes da estrutura social capitalista e das três condições básicas do processo de trabalho próprio do capitalismo: 1) separação entre trabalhadores e meios de produção, sendo que os trabalhadores só têm acesso aos meios ao vender sua força de trabalho; 2) liberdade dos trabalhadores de dispor de sua força de trabalho; 3) atuação dos trabalhadores na expansão de uma unidade de capital, que pertence ao comprador de sua força de trabalho, o capitalista.

Ou seja, as ciências humanas — investigação para compreender as relações do homem consigo mesmo, com os outros, com a transcendência e com a natureza - surgiram em função da necessidade de produção capitalista, do desenvolvimento da própria produção ou do processo de trabalho. Assim se estabeleceram os diversos métodos das ciências, por exemplo a visão naturalista e a visão dialética, ora para auxiliar o desenvolvimento do próprio capitalismo, ora para compreendê-lo e criticálo - cada um dos quais enfocando a ciência com

${ }^{6}$ LEFEBVRE (1975) 
interesses próprios.

Assim, se a pedagogia tem como objeto de estudo a prática educacional e esta se apresenta, através dos tempos, com diferentes perspectivas ou visões de mundo, caracterizando-se por métodos diferenciados, é porque ela depende do pedagogo e de sua posição nas condições básicas do capitalismo. Por isso a pedagogia dispõe hoje de diferentes teorias pedagógicas para explicar a educação.

A pedagogia, ao mesmo tempo que apreende a prática educacional, vai além da descrição, da explicação, para buscar o sentido dessa realidade, através das relações entre os indivíduos. Compreendendo o indivíduo como unidade de múltiplas relações, podemos afirmar que essas relações são também relações educacionais, caracterizadas pelo processo e pelo produto delas mesmas. Assim, a pedagogia deve abarcar as múltiplas relações que o indivíduo tem durante toda a vida para tornar-se cada vez mais humano.

As concepções ou tendências pedagógicas que se mostram na realidade educacional ao longo da história tratam justamente dessas relações. Todavia, manifestam-se em função da fragmentação que ocorre na realidade ou, ainda, concebem os indivíduos por justaposição, não orgânica e ativamente, refletindo a prática educativa de modo também fragmentado, sem criticá-la.
Tanto a pedagogia com seu método metafísico quanto a pedagogia com seu método naturalista não podem ser, em si, compreendidas como ciências pedagógicas, na medida em que não tratam da prática educativa como um processo e um produto, ou seja, em seu movimento. Em certo momento, elas até podem analisar o produto da prática educativa, mas de modo fixo, acrítico e sem historicizar a própria prática educativa. Ao contrário, a pedagogia como ciência - aquela que concebe a prática educativa em seu movimento de processo e produto e como unidade de múltiplas relações - busca encontrar na prática educativa o homem transformador ou criador que transcende o mundo dado, natural, bem como almeja o processo de autoprodução do ser humano, que constitui precisamente a sua história?

Portanto, a ciência da pedagogia, como produção de conhecimento de uma área determinada - a educação - e com um método específico — o dialético - , é autônoma como as demais ciências do homem. A pedagogia deixa, assim, de ser concebida como um instrumento das ciências humanas e passa a revelar seus próprios problemas no campo do conhecimento, que atingem, direta ou indiretamente, a estrutura (modo de produção) ou a superestrutura (valores, crenças, ideologia) de determinada sociedade. É uma pedagogia que encara a educação como prática social.

VÁZQUEZ, 1987

\section{REFERÊNCIAS BIBLIOGRÁFICAS}

COELHO E SILVA, J.P.C. "Das implicações na educação à ciência da educação", in Revista portuguesa de Pedagogia. Portugal: Universidade de Coimbra, 1991.

DEBESSE, M.; MIALARET, G. Tratados das ciências pedagógicas. São Paulo: Nacional, 1974.

GAL, Roger. Situação atual da pedagogia. Portugal: Arménio Amado, 1965.

GRANGER, G.G. A razão. São Paulo: Difusão Européia do Livro, 1969.

LOPES, Regina Pereira. Burocracia na educação. São Paulo, 1988. Dissertação (Mestrado). Pontifícia Universidade Católica de São Paulo.

Pedagogia e emancipação humana. São Paulo: Olho d'água, 2000.

MARX, K. Manuscritos econômico-filosóficos in Os pensadores. São Paulo: Abril Cultural, 1974. O capital. São Paulo: Nova Cultural, livro I, v. 1, tomo 2, 1985.

MILIARET, Gaston. Introdução à Pedagogia. São Paulo: Atlas, 1977.

VÁZQUEZ, A. S. Filosofia da práxis. 2. ed. Rio de Janeiro: Paz e Terra, 1977.

VIEIRA PINTO, A. Ciência e existência. Rio de Janeiro: Paz e Terra, 1969. 